\title{
Apakah pendapatan asli daerah (PAD) mendorong ketimpangan distribusi pendapatan di Yogyakarta?
}

\author{
Dessy Rachmawatie
}

Prodi Ekonomi. Fakultas Ekonomi dan Bisnis. Universitas Muhammadiyah Yogyakarta

\begin{abstract}
Paradigm Development is a process in development to achieve a change. Inequality of income distribution is a problem that is quite a severe concern in all regions and developed and developing countries. This proves that Yogyakarta Province still has a relatively high level of inequality in income distribution. Problems in income distribution inequality can be influenced by various factors, such as Regional Original Income to income distribution inequality in 5 Regencies/Cities in Yogyakarta Province for the 20102020 period. This study uses secondary data with panel data analysis method with a period of 2010-2020, using the Fixed Effect Model approach. This analysis shows that Regional Original Income has a positive and significant influence on the inequality of income distribution in 5 regencies/cities in Yogyakarta Province.
\end{abstract}

*E-mail korespondensi: d.rahmawatie@umy.ac.id

Keywords: Income distribution inequality, Locally-generated income.

\begin{abstract}
Abstrak
Paradigma Pembangunan merupakan sebuah proses dalam pembangunan untuk mencapai sebuah perubahan. Ketimpangan distribusi pendapatan merupakan permasalahan yang cukup menjadi perhatian serius di seluruh daerah maupun negara maju maupun juga di negara berkembang. Hal ini membuktikan bahwa di Provinsi Yogyakarta masih memiliki tingkat ketimpangan distribusi pendapatan yang relative masih tinggi. Masalah dalam ketimpangan distribusi pendapatan dapat dipengaruhi oleh berbagai faktor seperti, Pendapatan Asli Daerah terhadap ketimpangan distribusi pendapatan 5 Kabupaten/Kota di Provinsi Yogyakarta periode 2010-2020. Penelitian ini menggunakan data sekunder dengan metode analisis data panel dengan periode waktu 2010-2020, dengan menggunakan metode pendekatan Fixed Effect Model. Hasil analisis ini menunjukan bahwa Pendapatan Asli Daerah memiliki penaruh positif dan signifikan terhadap ketimpangan distribusi pendapatan di 5 Kabupaten/Kota di Provinsi Yogyakarta.
\end{abstract}

Kata kunci: Ketimpangan distribusi pendapatan, Pendapatan asli daerah.

\section{PENDAHULUAN}

Menurut Badan Pusat Statistika (2010) permasalahan mendasar yang di hadapi setiap negara dalam kebijakan awal pembangunan ekonomi selain target mengejar pertumbuhan adalah aspek pemerataan hasil-hasil pembangunan ekonomi. Pertumbuhan ekonomi dapat didefenisikan sebagai perkembangan kegiatan dalam perekonomian yang menyebabkan barang dan jasa yang diproduksikan dalam masyarakat bertambah, pada setiap negara memiliki pertumbuhan ekonomi yang sangat pesat sehingga kesemapatan kerja penuh dapat dicapai terus menerus (Manduapessy, 2020). 
Pertumbuhan ekonomi di wilayah atau pada negara secara jangka panjang memperlihatkan peningkatan menunjukkan bahwa perekonomian suatu negara atau suatu wilayah tersebuat dalam keadaan yang stabil. Tetapi jika pertumbuhan suatu Negara atau wilayah tersebut menunjukkan penurunan atau menurun maka menunjukkan bahwa suatu wilayah tersebut dalam keadaa yang tidak baik. Maka dari itu suatu wilayah memiliki target laju pertumbuhan yang tinggi untuk tujuan serta perencanaan pembangunan suatu wilayahnya (Fauza, 2019). Paling minimum setiap negara harus berusaha agar tingkat pertumbuhan ekonominya melebihi dari tingkat pertambahan penduduk, agar pendapatan per kapita atau taraf kemakmuran masyarakat dapat ditingkatkan (Sukirno, 2010).

Dua masalah besar yang umumnya dihadapi oleh negara-negara berkembang, termasuk Indonesia, adalah kesenjangan ekonomi atau ketimpangan dalam distribusi pandapatan antara kelompok masyarakat berpendapatan tinggi dan kelompok masyarakat berpendapatan rendah serta tingkat kemiskinan atau jumlah orang berada di bawah garis kemiskinan (poverty line) (Sutrisno, 2018). Adanya gerakan pembangunan yang dilakukan, ketimpangan serta distribusi pendapatan dan kemiskinan ini menjadikan lingkar konflik yang cukup sulit teratasi (Fauza, 2019). Oleh karena itu muncul beberapa perdebatan terkait hubungan antara ketimpangan pendapatan dan pertumbuhan ekonomi (Sukirno, 2010).

Ketimpangan pendapatan ialah suatu kondisi dimana distribusi pendapatan yang diterima masyarakat tidak merata (Fauza, 2019). Perekonomian yang berhasil menjadi maju pada umumnya ketimpangan pendapatannya relatif rendah, yang berarti perkembangan ekonomi melibatkan peran serta luas masyarakat (Syawie, 2013)

Permasalahan-permasalahan yang terjadi pada penelitian sebelumnya yang telah dijelaskan pada paragraph diatas, sehingga peneliti melakukan penelitian dengan judul "Apakah Pendapatan Asli Daerah (PAD) Mendorong Ketimpangan Distribusi Pendapatan di Yogyakarta (2010-2020)"

\section{KAJIAN PUSTAKA}

\section{Pendapatan asli daerah}

Menurut Undang-Undang No. 28 Tahun 2009 pendapatan asli daerah adalah sumber keuangan daerah yang digali dari wilayah daerah yang bersangkutan yang terdiri dari hasil pajak daerah, hasil retribusi daerah, hasil pengelolaan kekayaan daerah yang dipisahkan dan lainlain pendapatan asli daerah yang sah.

Sumber PAD berasal dari pajak daerah, hasil retribusi daerah, hasil perusahaan milik daerah serta hasil pengolahan kekayaan daerah lainnya yang dipisahkan, dan lainlain pen- dapatan daerah yang sah (Taryono dan Ekwarso, 2012)

Menurut pasal 6 UU No. 33 Tahun 2004 ayat 1 dan 2 menyatakan sumber pendapatan daerah terdiri dari pendapatan asli daerah, Bagi hasil pajak dan bukan pajak Klasifikasi Pendapatan Asli Daerah berdasarkan Permendagri No. 13 Tahun 2006 terdiri dari: a).Pajak daerah, hasil pengelolaan kekayaan daerah yang dipisahkan, lain-lain pendapatan asli daerah yang sah yang ditransfer langsung ke kas daerah, dana perimbangan dan lain-lain pendapatan daerah yang sah dianggarkan pada SKPKD. b).Pajak daerah itu sendiri dibedakan menjadi dua kategori yaitu pajak daerah yang ditetapkan oleh peraturan daerah dan pajak Negara yang pengelolaan dan penggunaannya diserahkan kepada daerah. Menurut UU No. 34 Tahun 2000 jenis pajak Kabupaten/Kota yaitu pajak hotel, pajak restoran, pajak hiburan, pajak reklame, pajak penerangan jalan, 
pajak pengambilan bahan galian golongan c, pajak parkir. c).Retribusi daerah, komisi, potongan, keuntungan selisih nilai tukar rupiah, pendapatan dari penyelanggaraan pendidikan dan pelatihan, hasil penjualan kekayaan daerah yang tidak dipisahkan dan hasil pemanfaatan atau pendayagunaan kekayaan daerah yang tidak dipisahkan yang dibawah penguasaan pengguna anggaran/pengguna barang dianggarkan pada SKPD. Retribusi daerah terdiri dari 3 golongan yaitu retribusi jasa umum, jasa usaha, perizinan tertentu. d).Hasil pengelolaan kekayaan daerah yang dipisahkan yaitu penerimaan yang diperoleh dari hasil perusahaan milik daerah dan hasil pengelolaan kekayaan daerah yang dipisahkan. Menurut UU No. 33 Tahun 2004 jenis hasil pengelolaan daerah yang dipisahkan sebagai berikut: 1).Bagian laba dalam penyertaan modal terhadap perusahaan milik daerah/BUMD, 2). Bagian laba dalam penyertaan modal terhadap perusahaan milik Negara/BUMN, 2).Bagian laba dalam penyertaan modal terhadap perusahaan milik swasta maupun kelompok usaha masyarakat, 3).Pendapatan asli daerah yang sah menurut UU Nomor 33 Tahun 2004 mengklasifikasikan yang termasuk dalam pendapatan asli daerah yaitu: 1).Pendapatan bunga, 2).Komisi potongan maupun bentuk lain yang disebabkan oleh penjualan, pengadaan barang ataupun jasa oleh Pemerintah Daerah, 3).Keuntungan nilai tukar rupiah terhadap mata uang asing, 4).Jasa/Giro, dan 5).Hak penjualan kekayaan daeah yang tidak dipisahkan

\section{METODE}

Penelitian ini menggunakan metode analisis kuantitatif dengan menggunakan data sekunder. Data diperoleh dari Badan Pusat Satatistik Provinsi Daerah Istimewa Yogyakarta (BPS). Data yang diperoleh jenis data Time Series dan data silang (cross section) atau data panel periode 2010 sampai 2020. Data time series adalah data dari waktu ke waktu yang dikumpulkan secara berurutan pada setiap periode waktu (Torres et al., 2021), setelah data diolah dalam bentuk time series kemudian data di analisis menggunakan software Eviews 10.0 dengan metode analisis regresi time series.

\section{HASIL DAN PEMBAHASAN}

\section{Uji heteroskedastisitas}

Pada Tabel 1, menunjukkan bahwa nilai dari probabilitas pada masing-masing variabel independent, PAD yaitu $<0,05$ maka hasil uji heteroskedastisitas pada penelitian ini terbebas dari masalah Heteroskedastisitas.

Tabel 1. Hasil uji heteroskedastisitas

\begin{tabular}{lllll}
\hline Variabel & Coefficient & Std.Error & t-Statistic & Prob. \\
\hline LOG(C) & 47.89195 & 16.13321 & 2.968532 & 0.0047 \\
LOG(PDRB) & -1.546858 & 1.081603 & -1.430154 & 0.1593 \\
IPM & -0.166421 & 0.119993 & -1.386929 & 0.1720 \\
LOG(PAD) & 0.015042 & 0.010095 & 1.490067 & 0.1432 \\
R-squared = 0.764088 & & & & \\
\hline
\end{tabular}

Sumber: Data diolah, 2021 


\section{Uji multikolinearitas}

Pada Tabel 2 tidak menemukan adanya nilai matriks korelasi (correlation matrix) antar variabel yang besarnya di atas 0,90. Dengan demikian dapat disimpulkan bahwa tidak terdapat masalah multikolinearitas dalam model ini.

Tabel 2. Hasil uji multikolinearitas

\begin{tabular}{ccccc}
\hline & IG(LOG) & IPM & PAD(LOG) & PDRB(LOG) \\
\hline IG(LOG) & 1.000000 & 0.222725 & 0.391033 & 0.096158 \\
IPM & 0.222725 & 1.000000 & -0.052119 & 0.038466 \\
PAD(LOG) & 0.391033 & -0.052119 & 1.000000 & 0.541244 \\
PDRB(LOG) & 0.096158 & 0.038466 & 0.541244 & 1.000000 \\
\hline
\end{tabular}

Sumber: Data diolah, 2021

\section{Uji Chow}

Pada Tabel 3 didapatkan nilai Probabilitas. $0.004<$ (lebih besar) dari niali $\alpha=0.05$ maka dapat disimpulkan bahwa $\mathrm{H}_{0}$ ditolak, sehingga model yang baik dan dipilih adalah model Fixed Effect Model (FEM).

Tabel 3. Hasil uji Chow

\begin{tabular}{cccc}
\hline Effects Test & Statistic & d.f. & Probabilitas \\
\hline Cross-section F & 6.339066 & $(4,47)$ & 0.0004
\end{tabular}

Sumber: Data diolah, 2021

\section{Uji Hausman}

Pada Tabel 4 nilai pengujian statistic Chi Square dari perhitungan di atas adalah sebesar 44.934432 dan di peroleh nilai Probabilitas. $0.0000<$ (lebih kecil) dari $\alpha=0.05$ maka dapat di simpulkan H0 ditolak, sehingga model yang baik dan di pilh adalah model Fixed Effect (FEM).

Tabel 4. Hasil uji Hausman

\begin{tabular}{cccc} 
Test Summary & Chi-Sq. Statistic & Chi-Sq. d.f & Probabilitas \\
\hline Cross-section random & 44.934432 & 3 & 0.0000 \\
\hline
\end{tabular}

Sumber: Data diolah, 2021

\section{Estimasi model regresi dengan fixed effect}

Pada Tabel 5 maka dapat dibuat model analisis data panel terhadap ketimpangan distribusi pendapatan di DI. Yogyakarya.

Tabel 5. Hasil fixed effect model

\begin{tabular}{lc}
\hline $\begin{array}{l}\text { Variabel dependen: ketimpangan } \\
\text { pendapatan (indeks gini) }\end{array}$ & distribusi \\
LOG(PDRB?) & Fixed effect model \\
IPM? & 0.162210 \\
LOG(PAD?) & 0.028348 \\
\hline
\end{tabular}

Sumber: Data diolah, 2021 
Adapun persamaan sebagai berikut:

$\mathbf{Y}_{\mathrm{it}}=\alpha+\beta_{1}(\mathbf{P D R B})_{i t}+\boldsymbol{\beta}_{2}(\mathrm{IPM})_{i t}+\boldsymbol{\beta}_{3}(\mathbf{P A D})_{i t}+\mathbf{e t}$

Keterangan:

Y $\quad=$ Variabel dependen (ketimpangan distribusi pendapatan)

$\alpha \quad=$ Konstanta

$\beta_{123}=$ Koefisien Variabel 1,2,3 adalah jumlah variabel

PDRB $=$ Produk domestik regional bruto

IPM = Indeks pembangunan manusia

PAD = Pendapatan asli daerah

i $\quad=$ Kota Yogyakarta, Kab Bantul, Kab Sleman, Kab Kulonprogo, Kab Gunung Kidul

$\mathrm{t} \quad=2010-2020$

Dimana diperoleh hasil sebagai berikut:

$\mathrm{Y}_{\mathrm{it}}=\alpha+\beta_{1}(\mathrm{PDRB})_{i t}+\beta_{2}(\mathrm{IPM})_{i t}+\beta_{3}(\mathrm{PAD})_{i t}+$ et

$\mathrm{Y}_{\mathrm{it}}=-7.163016+0.162210(\mathrm{PDRB})_{i t}+0.028348(\mathrm{IPM})_{i t}+0.060539(\mathrm{PAD})_{i t}+$ et

Keterangan dari Tabel 5 dapat di interpretasikan model dari Ketimpangan Distribusi Pendapatan antar kabupaten dan kota di Provinsi Yogyakarta sebagai berikut:

$\alpha=-7.163016$ dapat diartikan bahwa apabila semua variabel independen (IPM, dan PAD) dianggap konstan atau tidak mengalami perubahan maka ketimpangan distribusi pendapatan sebesar $7.1 \%$.

$\beta_{3}=0.060539$ dapat diartikan bahwa ketika Pendapatan Asli Daerah (PAD) naik sebesar $1 \%$ maka angka ketimpangan mengalami penurunan sebesar $0.060 \%$. Pada model estimasi diatas dapat dilihat bahwa adanya pengaruh cross section yang berbeda di setiap Kabupaten/Kota terhadap ketimpangan distribusi pendapatam di provinsi DI. Yogyakarta. Kabupaten/Kota yang memiliki pengaruh cross section yang bernilai positif adalah Kab/Kota Bantul sebesar 0.056358 Kab/Kota Kulon Progo sebesar,0.261009 dan Kab/Kota Gunung Kidul sebesar, 0.256372 Sedangkan Kabupaten/Kota yang memiliki pengaruh cross section negatif adalah Kab/Kota Sleman sebesar -0.083127 dan Kab/Kota Yogyakarta sebesar -0.490612 .

\section{Uji parsial (t-statistik)}

Tabel 6. Hasil uji t-statistik

\begin{tabular}{llll}
\hline $\begin{array}{l}\text { Variabel dependen:ketimpangan distribusi } \\
\text { pendapatan (indeks gini) }\end{array}$ & Coefficient & t-Statistic & Probabilitas \\
\hline LOG(PDRB?) & 0.162210 & 1.468245 & 0.1487 \\
IPM? & 0.028348 & 2.546877 & 0.0142 \\
LOG(PAD?) & 0.060539 & 2.774210 & 0.0079 \\
\hline
\end{tabular}

Sumber: Data diolah, 2021

Pengujian variabel indeks pembangunan manusia (IPM) pengaruh IPM terhadap ketimpangan distribusi pendapatan berdasarkan hasil analisis yang didapatkan dengan nilai koefisien variabel IPM terhadap ketimpangan distribusi pendapatan adalah 0.028348 dan t-hitung atau t-statistik sebesar 2.546877 dengan nilai probabilitas 0.0142 (lebih kecil dari 0,05). Koefisien regresi IPM yang bernilai positif dan probabilitas lebih kecil dari standart probabilitas mengartikan bahwa variable IPM secara parsial berpengaruh positif 
dan signifikan terhadap ketimpangan distribusi pendapatan di Kabupaten/Kota Yogyakarta. Hal ini sesuai dengan pengujian secara statistic $\mathrm{H}_{0}$ dilotak dan $\mathrm{H}_{\mathrm{a}}$ diterima.

Pengaruh PAD terhadap ketimpangan distribusi pendapatan berdasarkan hasil analisis didapatkan PAD dengan nilai koefisien variabl PAD terhadap ketimpangan distribusi pendapatan adalah 0.060539 dan t-hitung atau t-statistik sebesar 2.774210 dengan nilai probabilitas 0.0079 (lebih kecil dari 0,05). Koefisien regresi PAD yang bernilai negatif yang dimana lebih besar dari standart probabilitas mengartikan bahwa variable PAD secara parsial berpengaruh positif dan signfikan terhadap ketimpangan distribusi pendapatan di Kabupaten/Kota Yogyakarta. Hal ini sesuai dengan pengujian secara statistic $\mathrm{H} 0$ di tolak dan $\mathrm{H}_{\mathrm{a}}$ di terima.

Tabel 7. Hasil secara keseluruhan (uji F)

\begin{tabular}{ll}
\hline Regresi fixed effect (FEM) & \\
\hline Prob>F & 0.000002 \\
Error Corelated & 0.208856 \\
R-Square & 0.542404 \\
F-Statistik & 7.958668 \\
Adj R-Square & 0.474251 \\
\hline
\end{tabular}

Sumber: Data diolah, 2021

\section{Uji simultan (F-statistik)}

Pada Tabel 7 diatas nilai dari F-Statistik sebesar 7.958668 dan nilai Probabilitas FStatistik sebesar 0.000002 maka dapat disimpulkan bahwa nilai Prob>F lebih kecil dari $\alpha=0,05$ maka dapat dikatakan variabel independent secara bersama-sama sehingga memiliki pengaruh terhadap variabel dependen

Koefisien determinasi $\left(\mathbf{R}^{2}\right)$

Tabel 8. Hasil uji determinan $\left(\mathrm{R}^{2}\right)$

\begin{tabular}{ll}
\hline \multicolumn{1}{c}{ Regresi fixed effect (FEM) } & \\
\hline Prob>F & 0.000002 \\
Error Corelated & 0.208856 \\
R-Square & 0.542404 \\
F-Statistik & 7.958668 \\
Adj R-Square & 0.474251 \\
\hline
\end{tabular}

Sumber: Data diolah, 2021

Pada Tabel 8 menunjukkan hasil dari R-Square sebesar 0.542404 yang berarti ketimpangan distribusi pendapatan di 5 Kabupaten/Kota di Provinsi Yogyakarta memiliki perubahan sebesar 54,24\% yang di pengaruhi oleh PDRB, IPM,dan PAD. Sedangkan nilai $45,76 \%$ dipengaruhi oleh variabel diluar penelitian.

\section{KESIMPULAN DAN SARAN}

\section{Kesimpulan}

Dari hasil penelitian ini mengenai ketimpangan distribusi pendapatan di 5 (lima) Kabupaten/Kota di Provinsi Yogyakarta periode 2010-2020, yaitu Kota Yogyakarta, Kab Sleman, Kab Bantul, Kab Kulon Progo, dan Kab Gunung kidul. Dengan menggunakan variabel dependen ketimpangan distribusi pendapatan dan variabel independenya yaitu variabel IPM dan PAD dapat di simpulkan variabel Pendapatan Asli Daerah (PAD) berpengaruh positif dan signifikan terhadap ketimpangan distribusi pendapatan di 5 
Kabupaten/Kota di Provinsi Yogyakarta periode 2010-2020. Hal ini menunjukan bahwa ketika pendapatan asli daerah meningkat bisa mengoptimalkan peningkatan pembelanjaan karena merupakan salah satu sumber pendapatan daerah di 5 Kabupaten/Kota di Provinsi Yogyakarta.

\section{Saran}

Pendapatan asli daerah (PAD) merupakan suatu bentuk desentralisasi fiskal yang dapat menyebabkan ketimpangan. Perlunya efektivitas serta peran desentralisasi fiskal memungkinkan pemerintah daerah provinsi Yogyakarta untuk memperoleh sumber dana agar dapat melakukan pembangunan, yaitu yang berasal dari pendapatan asli daerahnya (PAD). Kebijakan ini diharapkan akan memberikan dampak positif pada transformasi ekonomi, transformasi tenaga kerja dan transformasi kelembagaan, sehingga dapat meningkatkan pertumbuhan ekonomi dan efektifitas pembangunan di Daerah Istimewa Yogyakarta.

\section{DAFTAR PUSTAKA}

Afandi, A., Rantung, V. P., \& Marashdeh, H. (2017). Determinant of income inequality in Indonesia. Economic Journal of Emerging Markets, 9(2), 159-171. https://doi.org/10.20885/ejem.vol9.iss2.art5

Agustin, M. A. (2017). Ketimpangan Pendapatan di Jawa Timur Tahun 2011-2015

Apriana, D., \& Suryanto, R. (2010). Analisis hubungan antara belanja modal, pendapatan asli daerah, kemandirian daerah dan pertumbuhan ekonomi daerah. Jurnal Akuntansi \& Investasi, 11(1), 68-79.

Arifianto, W., \& Setiyono, I. (2013). Pengaruh pertumbuhan ekonomi terhadap distribusi pendapatan di Indonesia. Jurnal UNS, 1(1), 1-16.

Astuti, R. D. (2015). Analisis determinan ketimpangan distribusi pendapatan di DIY Periode 2005-2013. Tirtayasa Ekonomika, 15(1), 17-30.

Bappeda DIY. (2018). Arah kebijakan pembangunan DIY 2017-2022.

Chen, H. K., \& Chou, H. W. (2006a). Supply chain network equilibrium with asymmetric variable demand and cost functions.

Dixit, A.K. \& Norman, V. (1980). Theory of International trade. Cambridge University Press: Cambridge.

Durlauf, S. N., Johnson, P. A., \& Temple, J. R. (2005). Growth Econometrics. Dalam P. Aghion, \& S. N. Durlauf (Editor), Handbook of Economic Growth. IA. Amsterdam: North-Holland.

Fauza, R. R. (2019). Analisis faktor-faktor yang mempengaruhi ketimpangan distribusi pendapatan di Daerah Istimewa Yogyakarta Tahun 2010-2016. Universitas Islam Indonesia.

Hudiyanto (2017),Ekonomi Pembangunan, J1 Menur 187 Rt.06 Kasihaan Bantul : Lingkar Media. Yogyakarta.

Kremer, M. \& Chen, D. (2000). Income Distribution Dynemics with Endogenous Fertility. Working Paper, 7530.

Manduapessy, R. L. (2020). Pengaruh Pendapatan Asli Daerah (PAD), Dana Perimbangan Terhadap Pertumbuhan Ekonomi Dan Kemiskinan Di Kabupaten Mimika. Jurnal Kritis, 4(2), 39-57.

Rahayu, Y. (2018). Analisis pengaruh indeks pembangunan manusia, PDRB per kapita, dan jumlah pengangguran terhadap jumlah penduduk miskin di Provinsi Jambi. Ekonomis: Journal of Economics and Business, 2(1), 165-174.

Rangazas, P. (2000). Schooling and economic growth: a King-Rebelo experiment with 
human capital. Journal of Monetary Economics, 46(2), 397-416.

Sutrisno, C. S. (2018). Analisis faktor-faktor yang mempengaruhi ketimpangan distribusi pendapatan antar Kabupaten/Kota di Provinsi Jawa Tengah Tahun 2010-2015.

Sukirno, Sadono. (2010). Makroekonomi teori pengantar. Ed.3. PT. Raja Grafindo Persada: Jakarta.

Syawie, M. (2013). Ketimpangan pendapatan dan penurunan kesejahteraan masyarakat. Informasi, 18(02), 95-104.

Taryono., \& Ekwarso H. (2012). Analisis pengeluaran dan distribusi pendapatan penduduk Kabupaten/ Kota di Provinsi Riau Tahun 2008 dan 2009.Jurnal Sosial Ekonomi Pembangunan. 2(5).

Thomas, Trevor M. (1956). Wales: land of mines and quarries. Geographical Review, 46(1), 59-81. http://www.jstor.org/stable/pdfplus/211962.pdf (Diakses 30 Juni 2005). 